\title{
DENOMINACIÓN DE ORIGEN DEL CAFÉ DE SAN RAFAEL DEL NORTE
}

Ing. Alba Veranay Díaz Corrales Departamento Coordinación de Agroindustria.

Universidad Nacional de Ingeniería. UNI-Norte Sede Estelí.
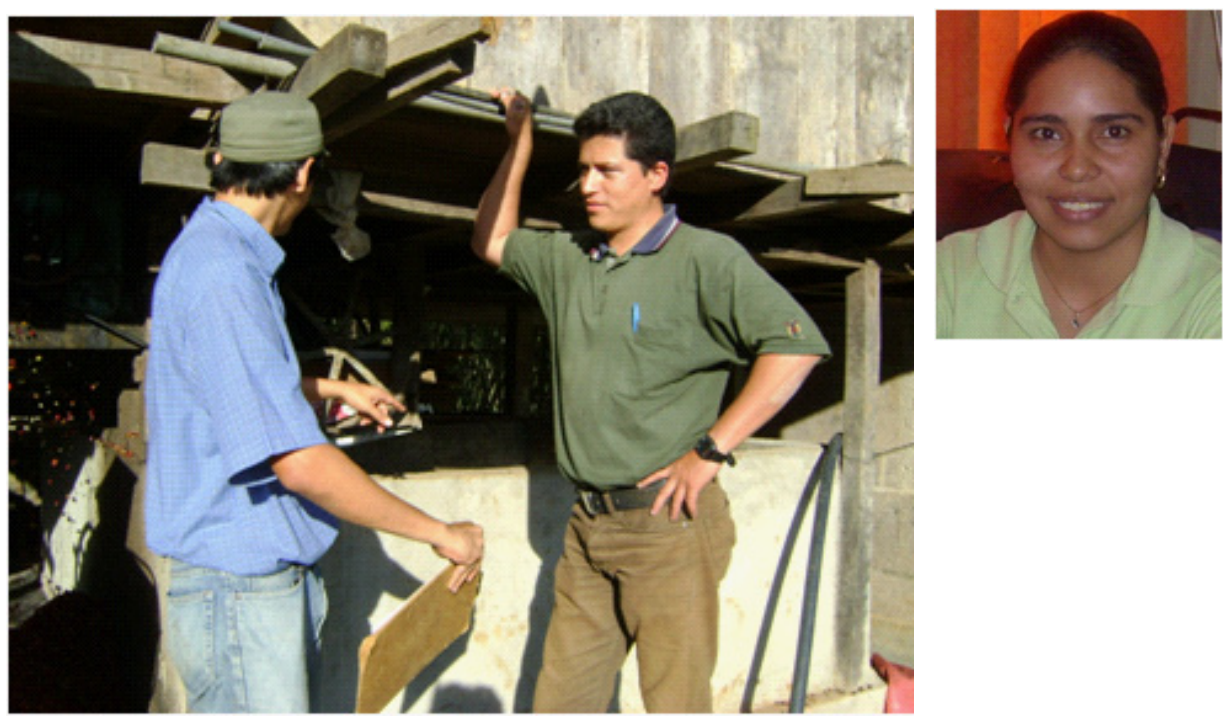

Estudiante, realizando entrevista a técnico de cooperativa Tepeyac.

\section{RESUMEN}

El problema principal de los productores de café de San Rafael del Norte, es producir un café de calidad y no obtener del mismo los beneficios económicos correspondientes, por no desarrollar una promoción hacia la obtención de la denominación de origen, a pesar que el país ya cuenta con un marco legal respectivo. Esta investigación, se enfoca a la tramitación de la denominación de origen registrando sus atributos y particularidades en un área específica, correspondiente al departamento de Jinotega, municipio de San Rafael del Norte, con las cooperativas Flor de Pino y Tepeyac, pertenecientes al grupo UCOSEMUN. Para lograr la denominación de Origen se realizó caracterización del municipio de San Rafael del Norte y la ubicación de cada una de las fincas. Se realizó la toma de 160 muestras de café para el análisis físicos-químicos, organolépticos y bioquímicos para la caracterización del café, tanto de San Rafael como Dipilto (testigo). En los resultados de calidad organoléptica, se obtuvo un puntaje promedio total para San Rafael del Norte de 81.5. y en cuanto al parámetro de acidez se obtuvo un puntaje de 6.5. Se esta trabajando en la Norma Técnica del café de San Rafael del Norte, para solicitud y tramitación de la denominación de Origen (D.O) del café ante el MIFIC. Una vez alcanzada la D.O se obtendrán los siguientes beneficios: Diferenciar el producto café de San Rafael por sus características especiales, de otros cafés, y será considerado como un café de alta calidad en mercados. Se garantizará al consumidor un producto de calidad con características específicas. Mejorará la organización del sector productivo, facilitando el acceso del producto a mercados nacionales e internacionales. Mejores precios a los pequeños y medianos productores organizados en cooperativas de San Rafael del Norte, Jinotega, al comercializar el café con un origen reconocido.

\section{INTRODUCCIÓN}

El café por muchos años ha sido uno de los principales rubros agro-exportadores de Nicaragua con una repercusión significativa desde el punto de vista económico y social, por su efecto sobre el ingreso nacional y la generación de empleo.

El principal mercado de exportación de café de Nicaragua es Estado Unidos que representa el 35\% de la producción, seguido de Alemania con un 30\% y el restante 35\% distribuido entre: España, Japón, Inglaterra, Francia, Holanda, Finlandia y Bélgica. (López Núñez, 2007). 
Mientras el consumo de café en general está bajando en los Estados Unidos, el consumo de café especial está creciendo. Los compradores de café especial no sólo buscan granos que cumplan con ciertos parámetros de calidad. Estos compradores también buscan variedades de café con ciertas características de sabor. La Asociación del Café Especial de los Estados Unidos (SCAA) define el café especial como "un café que no tiene defectos y tiene un sabor distinto en la taza".

Según el CEPAL (Revista Envío, 2004), el 80\% del café nicaragüense es elegible para que sea comercializado en los mercados de café especiales. Jean Jacques Perriot (catador internacional) considera que el café de Nicaragua es poco reconocido en el mercado internacional, no por carecer de calidad, sino porque no se ha trabajado en un sello propio que lo identifique en el mercado tanto nacional como internacional.

Actualmente el mercado mundial del café se está perfilando hacia un producto de calidad con reconocimiento original. En la comercialización tanto a nivel nacional como internacional del café, el productor está haciendo uso de la Denominación de Origen como distintivos implementados y de propiedad de los productores de las zonas en donde se establecen las mismas. Esta distinción, elaborada, inscrita, vigilada y transada por los productores con el apoyo de los compradores de café, se vuelve una garantía, tanto para los productores que están entregando un producto de calidad, con características definidas y aceptadas por los compradores, y los compradores tendrán la garantía que el producto por el que pagaron mantendrá las características que los hizo escoger determinado café y que lo distingue de otros café de otras regiones. Para el productor, esto representa una herramienta de negociación con el comprador que le asegura una justa remuneración.

La existencia de un mercado en el cual el Origen es un factor de remuneración, explica el interés nuevo de los países productores de café, entre ellos Nicaragua, por la certificación de las Denominaciones de Origen. Estas calificaciones han comprobado ser útiles en muchos productos, especialmente vinos, licores y quesos. El Champagne, el Cognac, el Tequila son ejemplos de denominaciones de origen exitosos. Honduras y Costa Rica cuentan con experiencias en la implementación de las denominaciones de Origen en café.
Si se quiere tener reconocimiento internacional por la calidad de los cafés producidos en Nicaragua, se debe ir desarrollando denominaciones de origen, actividad nueva en este rubro, a pesar que ya hay legislación nacional sobre el tema. Se hace urgente desarrollar capacidades para tener denominación de origen en todas las zonas donde se produce café de calidad. Estas denominaciones, una vez que tengan reconocimiento internacional, permitirán encontrar mercados estables y de mejor precio que los actuales.

Se entiende por Denominación de Origen (DO), la denominación de un país, de una región o de una localidad, que sirve para designar el origen de un producto cuya calidad o características se deben exclusiva o esencialmente al medio geográfico, incluyendo los factores naturales y factores humanos (Pohlan Jurgen, 2006). Es una garantía de origen, una garantía del proceso de producción y una garantía de calidad del producto, y en definitiva una garantía de constancia de las características del producto a través de los años, factor de alta importancia para el comprador y consumidor.

El problema principal de los productores de café de San Rafael del Norte, es producir un café de calidad y no obtener del mismo los beneficios económicos correspondientes, por no desarrollar una promoción hacia la obtención de la denominación de origen, a pesar que el país ya cuenta con un marco legal respectivo.

El objetivo de esta investigación, se enfoca hacia desarrollar, validar e implementar un modelo de Denominación de Origen para el Café producido en el municipio de San Rafael del Norte, como una herramienta que proteja su buen nombre de usurpaciones, imitaciones, para que los beneficios económicos derivados de la reputación colectiva sean aprovechados exclusivamente por los productores de la región, provocando así una mejoría en la calidad de vida de los productores y dando garantía del origen y calidad del producto a los consumidores.

\section{MATERIALES Y MÉTODOS}

Para la caracterización agro socioeconómica, se realizaron 70 encuestas en el municipio de San Rafael del Norte y Dipilto, siendo este último utilizado como testigo por caracterizarse por producir café de calidad. 
Las variables climáticas que se tomaron en cuentan y que alteran principalmente el tipo y calidad del café fueron latitud, altitud y la pluviometría anual.

Delimitación precisa del territorio y de las fincas de los productores pertenecientes a las cooperativas Tepeyac y Flor de Pino, que estarán en la Denominación de Origen. La georeferenciación se realizó utilizando GPS de precisión. La edición de mapas se está trabajando con programas especializados.

Realización de talleres con los productores, técnicos y representantes de las cooperativas involucradas en San Rafael del Norte, con el objetivo de dar a conocer lo que es la denominación de origen, qué beneficios futuros pueden obtener utilizando esta herramienta, elección de nombre de la denominación de Origen y selección de representantes legales de ambas cooperativa.

Se recolectaron 70 muestras de café para la realización de análisis físicos, organolépticos y bioquímicos para realizar la caracterización del café del municipio de San Rafael del Norte. Los análisis de físicos y organolépticos se realizaron en el laboratorio de calidad, en el beneficio de PRODECOOP en Palacaguina. Los análisis bioquímicos cafeína y carbohidratos totales en el laboratorio de Alimentos LABAL del Ministerio de fomento de la industria y comercio MIFIC. Para conservar las muestras de café, se empacaron al vacío.

Elaboración de norma técnica de calidad, del café de San Rafael del Norte, la que se someterá ante el Ministerio de Fomento, Industria y Comercio (MIFIC).

\section{RESULTADOS PRELIMINARES}

Del total de 160 muestras tomadas, 58 de San Rafael del Norte y 102 de Dipilto, en el análisis organoléptico por medio de catación (perfil de taza) se obtuvo que el café de San Rafael del Norte es menos ácido que el café de Dipilto. En la figura 1 se puede observar que en los parámetros organolépticos aroma, sabor y sabor residual no se encontró diferencias estadísticas entre el café de Dipilto y San Rafael del Norte. En cambio en la acidez si se encontró diferencias, siendo éste uno de los parámetros importantes en la determinación de la calidad.

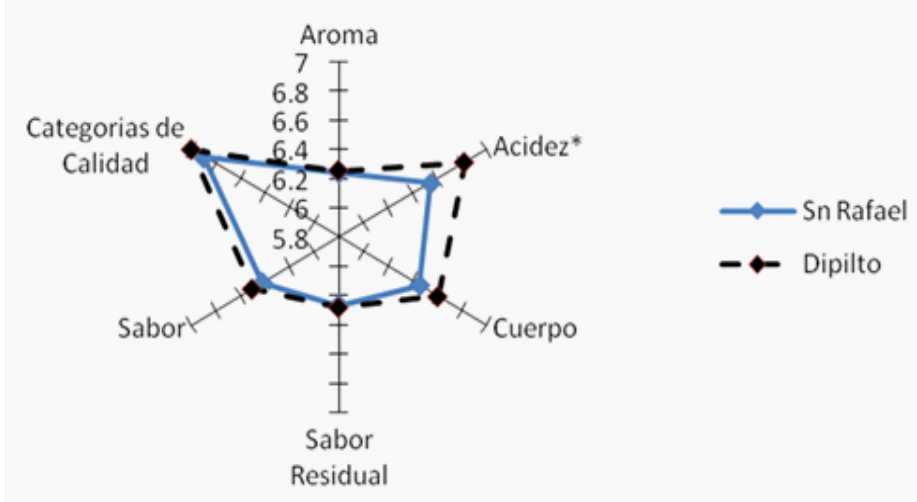

Figura: 1 Atributos del café San Rafael delNortey Dipilto.

Con el programa SPSS se realizó análisis discriminante multivariante, para crear un modelo que permita predecir a qué población pertenece una muestra de café tomada al azar de los municipios de San Rafael del Norte y Dipilto. Se seleccionaron las variables relacionadas con granulometríia del café y atributos de taza. La función discriminante no estandarizada obtenida es: $\mathrm{D}=$ valor del tamiza15 (26.866) + valor de la Acidez $(-0.929)=9.989$. El valor de D, permite ubicar la muestra de café a uno de los municipios con una probabilidad de pertenencia asociada. El centroide obtenido para San Rafael del Norte fue de 0.711 y para Dipilto -0.398 .

En la tabla 1 se muestra el número de resultados clasificados sobre el total de muestra utilizada en el análisis discriminante.

Tabla 1: Resultados de la clasificación ${ }^{2}$

\begin{tabular}{|cl|c|c|c|}
\hline & & \multicolumn{2}{|c|}{$\begin{array}{c}\text { Grupo de pertenencia } \\
\text { pronosticado }\end{array}$} & \multirow{2}{*}{ Total } \\
\cline { 3 - 4 } & Municipio & San Rafael & Dipilto & \\
\hline Original Recuento & San Rafael & 40 & 17 & 57 \\
& Dipilto & 25 & 77 & 102 \\
\cline { 3 - 4 }$\%$ & San Rafael & $\mathbf{7 0 . 2}$ & 29.8 & 100.0 \\
& Dipilto & 24.5 & $\mathbf{7 5 . 5}$ & 100.0 \\
\hline
\end{tabular}

a. Clasificados correctamente el $73.6 \%$ de los casos agrupados originales.

El nombre seleccionado para el registro de la denominación de origen, es Café Loma Azul San Rafael del Norte. En los resultados en cuanto a latitud en el municipio de Dipilto tiene un valor promedio de $1262 \mathrm{Msnm}$ y San Rafael del Norte 1141 Msnm, presentando mayor altitud el municipio de Dipilto. 


\section{Revista EL HIGO}

\section{CONCLUSIONES}

Con el presente estudio, se está logrando detectar diferencias entre el café de San Rafael del Norte y Dipilto, tanto en condiciones geográficas como en el producto final. Lo que indica que cada uno de ellos tiene sus propias características.

Se está estableciendo una metodología que permitirá poder aplicarla en otros lugares de Nicaragua donde quiera protegerse el café de una zona y obtener los beneficios económicos.

Se están procesando los datos estadísticamente, para realizar las etapas finales de la investigación.

\section{LITERATURA CITADA}

POHLAN JURGEN. SOTO LORENA. 2006. El Ca-

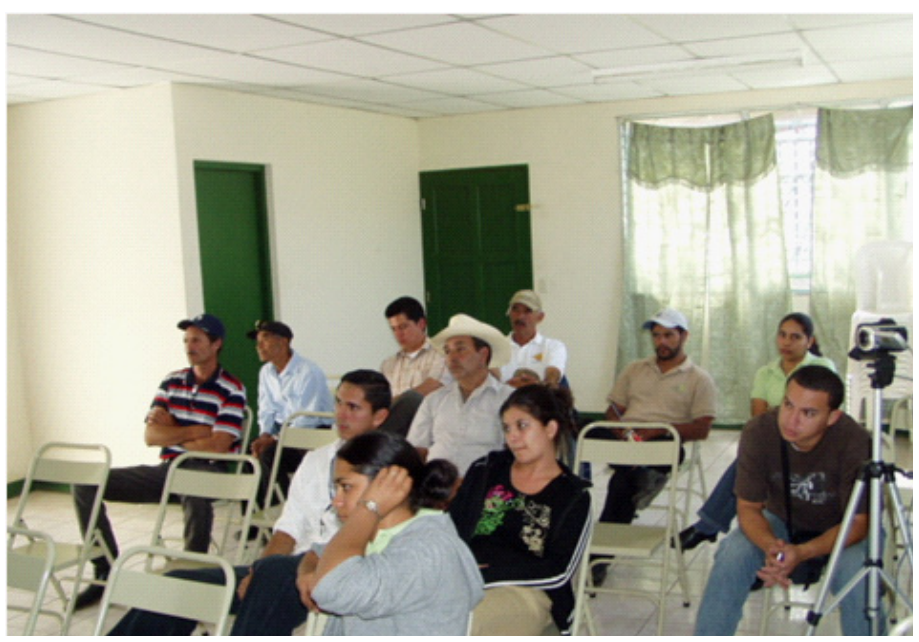

Taller con técnicos de cooperativas Tepeyac y Flor de Pino, en San Rafael del Norte.

fetal del futuro Realidades y Visiones. Agosto 2006. ECOSUR, El Colegio de la Frontera Sur, Chiapas, México Rheinische Friedrich- Wilhelms-U niversitat Bonn, Alemania

LÓPEZ NUÑEZ OSWALDO. 2007. El sector cafetalero de las Segovia, ante el Mercado Mundial. Universidad Nacional Autónoma de Nicaragua. Centro Universitario Regional del Norte (CURN). Universidad de Barcelona España (UB).

SOPPEXCCA. 2007. Unión de Cooperativas Agropecuarias. Guía del Mercado de café de Estados Unidos. TransFair.

PEDROZA H. y DICOVSKIY. 2006. Sistema de Análisis Estadísticos con SPSS. Managua, Nicaragua.

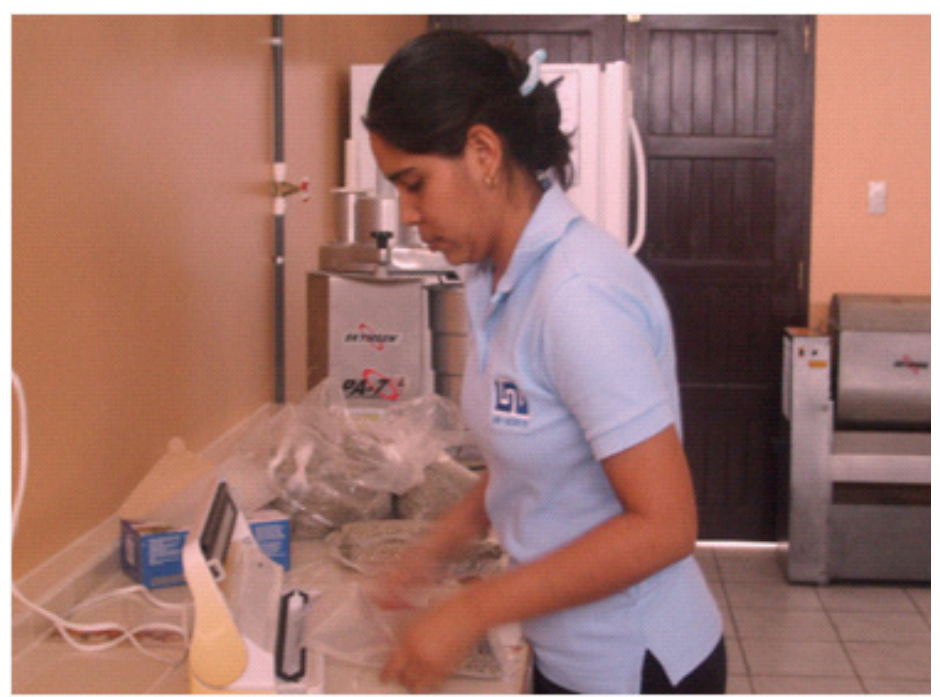

Ing. Alba Díaz C. empacando muestras de café de San Rafael 